\title{
PERANCANGAN SISTEM INFORMASI PEMANTAUAN PERANGKAT VSAT PADA PT MULTIMEDIA NUSANTARA BERBASIS JAVA
}

\author{
Muhammad Zulpan \\ Program Studi Teknik Informatika, Fakultas Teknik dan Ilmu Komputer, \\ Universitas Indraprasta PGRI \\ Jalan Raya Tengah No 80, Kelurahan Gedong, Pasar Rebo, Jakarta Timur \\ zulpanadidev@gmail.com
}

\begin{abstract}
Abstrak
Semakin meningkatnya jumlah pemasukan dan pengeluaran perangkat vsat akan semakin kompleks masalah pada perusahaan sehingga diperlukan adanya pengawasan secara terus-menerus untuk menjamin pendataan perangkat. Sistem informasi pemantauan progres perangkat merupakan aplikasi yang mampu untuk memantau pemasukan dan pengeluaran perangkat berbasis java yang dilengkapi dengan sistem database untuk menyimpan dan mengolah perangkat. Metode penelitian yang digunakan adalah metode penelitian kualitatif untuk mendapatkan progres data perangkat sesuai yang terjadi di lapangan. Tujuan dari Penelitian ini untuk memudahkan perusahaan PT Multimedia Nusantara dalam sistem informasi pemasukan dan pengeluaran, baik dari waktu, tenaga, pikiran maupun keamanan dalam penyimpanan yang membuat operasional perusahaan lebih efektif.
\end{abstract}

Kata Kunci: Aplikasi, Pemantauan, Java.

\begin{abstract}
The increasing amount of revenue and expenditure of vsat devices will be more complex problems in the company so that there is a need for continuous supervision to ensure the collection of devices. Device progress monitoring information system is an application that is able to monitor the income and expenditure of java-based devices equipped with a database system to store and process devices. The research method used is a qualitative research method to get the progress of device data as it happens in the field. The purpose of this research is to facilitate the company PT Multimedia Nusantara in information systems of income and expenditure, both from time, energy, mind and security in storage that makes the company's operations more effective.
\end{abstract}

Keyword: Application, Monitoring, Java.

\section{PENDAHULUAN}

Berkembangnya kemajuannya teknologi yang semakin pesat, khususnya teknologi di bidang informasi yang berbasiskan komputer, menuntut manusia untuk mengikuti dan menerapkannya di segala bidang agar tercapainya kemajuan teknologi. Dengan adanya kemajuan teknologi tersebut diharapakan dapat membantu pekerjaan atau usaha seseorang termasuk salah satunya di bidang pemantauan. Perkembangan sistem informasi berbasis komputer pada saat ini sudah menjadi tuntutan utama pada setiap perusahaan dalam skala besar maupun kecil sebagai sistem pengolahan data. Informasi menjadi bagian terpenting pada setiap pengambilan keputusan dalam suatu organisasi. Informasi yang tepat, akurat dapat membantu perusahaan dalam mencapai tujuan perusahaan tersebut.

Suatu sistem monitoring data perangkat yang baik akan meningkatkan produktifitas dan kinerja dari perusahaan. Dalam melakukan penelitian di PT Multimedia Nusantara peneliti menemukan permasalahan yaitu adanya kesalahan dalam beberapa proses pemantauan dan penyampaian informasi. Terutama dalam proses pemasukan dan pengeluaran perangkat kemudian pelaporan hasil proses pengelolaan perangkat VSAT yang dibutuhkan oleh pihak manajemen, sering terdapat kesalahan dan ketidkasesuaian masalah sehingga masalah itu dapat menghambat aktivitas perusahaan, terlebih lagi sampai menimbulkan kerugiaan bagi perusahaan. Oleh karena itu 
diperlukan suatu sistem informasi yang dapat mendukung pengelolaan informasi yang ada serta mampu menyelesaikan masalah yang ada dengan menggunakan sistem terkomputerisasi.

Berdasarkan hal tersebut pada studi ini mencoba menjawab tantangan dan berusaha mengembangkan kemampuan dibidang informatika untuk membuat sebuah perangkat lunak (software) yang dapat membantu dalam pengambilan keputusan dan memberikan kemudahan dalam pengolahan sebuah informasi.

\section{PENELITIAN RELEVAN}

Dalam melakukan penelitian tentang Perancangan Sistem Informasi Pemantauan Progres Perangkat pada PT . Multimedia Nusantara peneliti menggunakan bahan referensi dari sumber, serta beberapa buku. Penelitian oleh (Yakub, 2012) dengan judul Pengantar Sistem Informasi dan (Hutahaean, Jeperson, 2015) Sistem Informasi Manajemen, tujuan dari penelitian tersebut adalah membuat sistem komputerisasi pemantauan barang yang telah memiliki fitur pengolahan data dan instalasi barang, yang dapat melakukan pembuatan laporan instalasi, laporan dan stok barang secara otomatisasi sehingga sistem ini dapat mendukung pengolahan data dengan lebih efektif dan efisien.

\section{METODE PENELITIAN}

Metode pengumpulan data yang dilakukan oleh peneliti untuk mendapatkan data-data serta informasi untuk mendukung penyempurnaan hasil dari penelitian ini antara lain:

\section{Angket}

Angket/Kuesioner merupakan teknik pengumpulan data yang dilakukan dengan cara memberi seperangkat pertanyaan atau pernyataan tertulis kepada responden untuk dijawab ataupun direspon.

\section{Studi Lapangan}

Bertempat di PT Multimedia Nusantara pada bulan maret 2020, peneliti lakukan studi lapangan untuk melihat langsung terhadap sistem informasi monitoring progres perangkat.

\section{Kuesioner}

Teknik pengumpulan data melalui kuesioner ini, merupakan data-data penting yang digunakan oleh peneliti untuk memperkuat permasalahan yang ada. Dalam teknik pengumpulan data ini diutarakan pertanyaan-pertanyaan yang telah dilengkapi oleh jumlah alternatif jawaban dan responden hanya diberikan kebebasan untuk memilih salah satu dari jawaban yang paling dianggap tepat dan benar.

\section{Sumber Data}

Data dan informasi yang diperoleh untuk menguatkan penelitian ini, diambil dari 2 sumber yaitu sumber data primer yang diperoleh langsung dari responden melalui kuesioner dan sumber data sekunder yang merupakan data pendukung untuk melengkapi data primer yang diperoleh melalui tanya jawab langsung atau dokumen.

\section{Metode Pengembangan Sistem}

Dalam perancangan Sistem Informasi Progres Monitoring Perangkat, peneliti mengembangkan sistem melalui langkah-langkah antara lain:

\section{Analisis Kebutuhan}

Sebelum membuat sistem aplikasi, peneliti memulainya dengan memahami kebutuhan pengguna sistem dan memahami keinginan pengguna sistem tersebut.

\section{Studi Kepustakaan}

Studi kepustakaan bertujuan untuk mempelajari dan memahami landasan teori yang berhubungan dengan analisa kebutuhan. Studi kepustakaan ini bisa berdasarkan referensi.

\section{Perancangan Sistem}

Perancangan sistem dilakukan agar sistem yang akan dibuat sesuai dengan kebutuhan pengguna. 


\section{Implementasi Sistem dan Evaluasi Sistem}

Implementasi atau pengkodean adalah proses menterjemahkan dokumen hasil desain menjadi baris-baris perintah bahasa pemrograman komputer.

5. Pengujian

Pengujian adalah proses untuk memastikan apakah semua fungsi sistem bekerja dengan baik dan mencari apakah masih ada kesalahan pada sistem.

\section{Mengambil Kesimpulan}

Apakah fungsi yang terdapat pada sistem informasi monitoring progres perangkat VSAT pada PT Multimedia Nusantara Indonesia sudah dapat berfungsi sebagaimana yang dimaksud.

\section{HASIL DAN PEMBAHASAN}

Diagram Konteks Sistem yang diusulkan

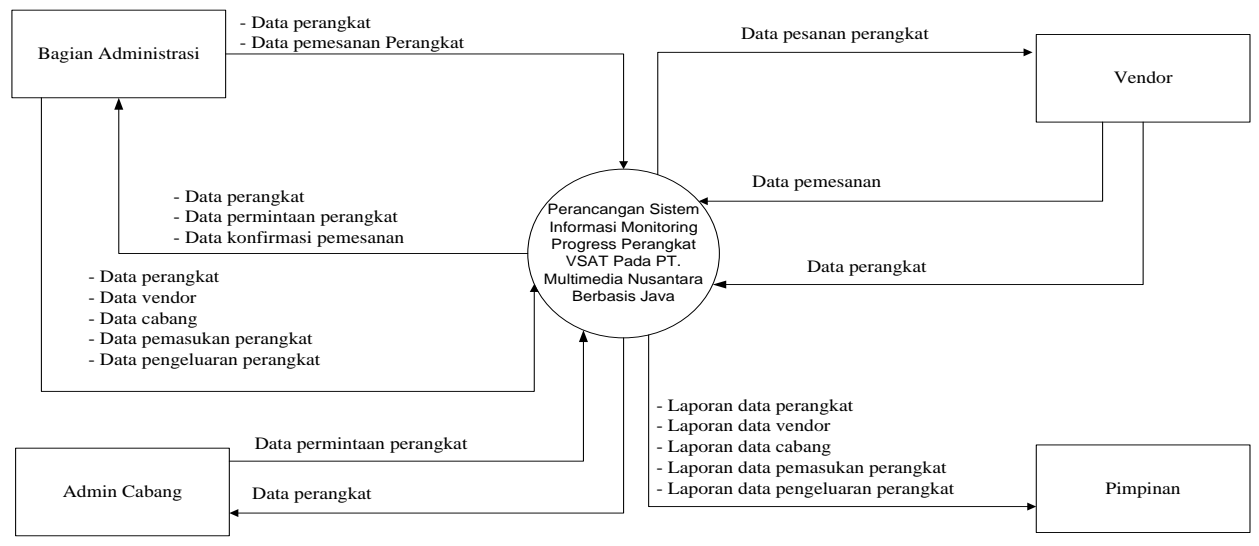

Gambar 1. Diagram Konteks Sistem yang Diusulkan

\section{Diagram rinci level 0 Sistem yang Diusulkan}

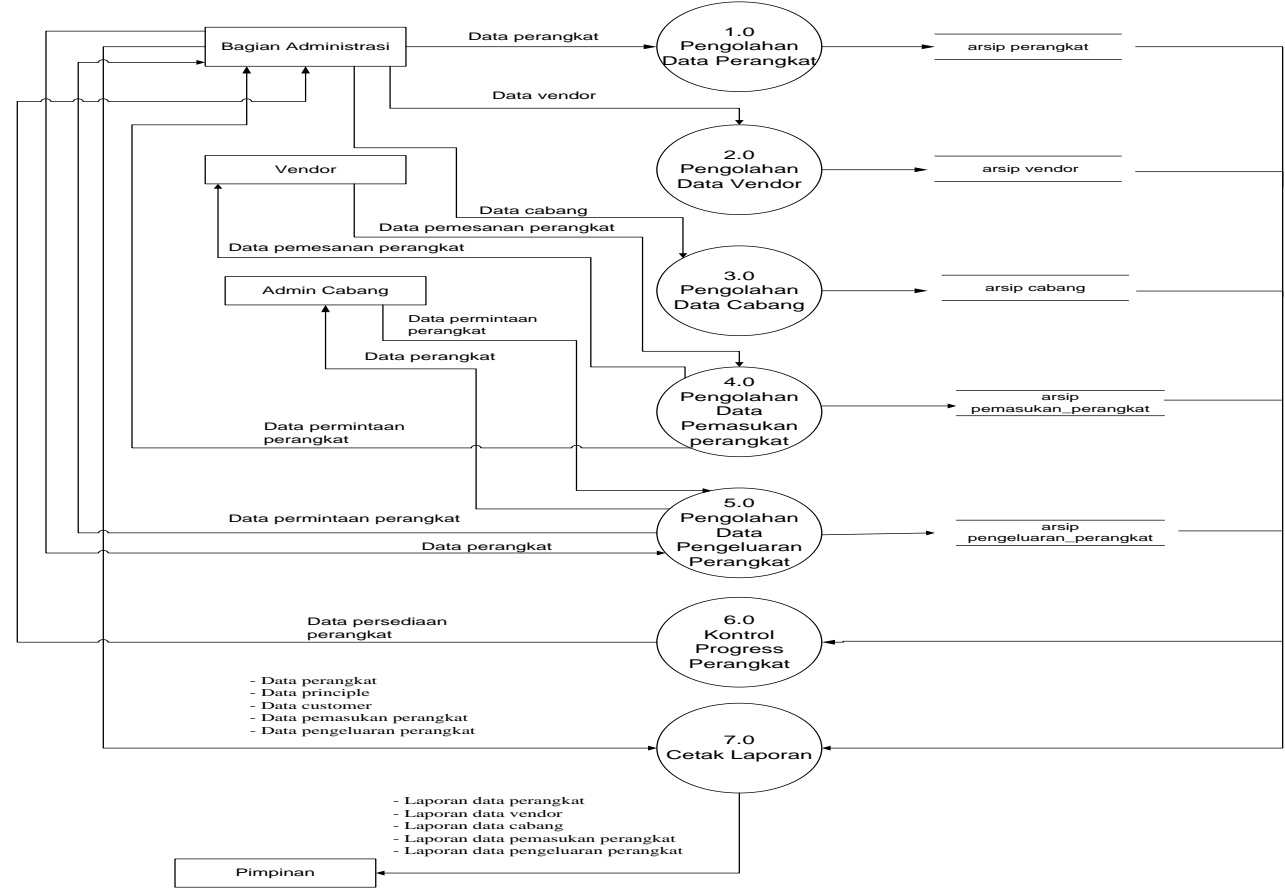

Gambar 2. Diagram Rinci level 0 Sistem yang Diusulkan 


\section{Entity Relationship Diagram}

Entity Relationship Diagram (ERD) merupakan suatu model untuk menjelaskan hubungan antar data dalam basis data berdasarkan objek-objek dasar data yang mempunyai hubungan antar relasi, untuk memodelkan struktur data dan hubungan antar data untuk menggambarkannya digunakan beberapa notasi dan symbol.

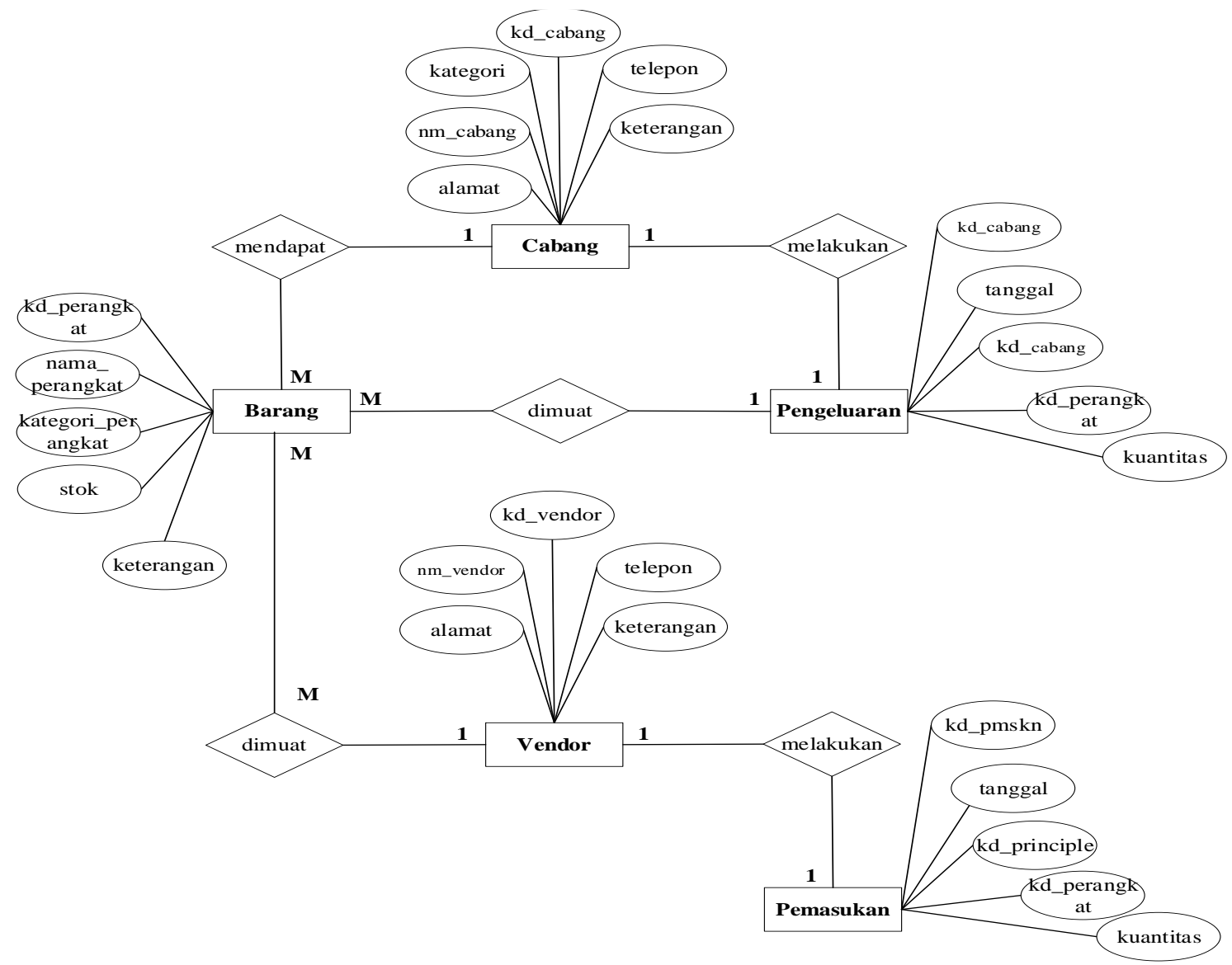

Gambar 3. Entity Relationship Diagram

\section{Tampilan Aplikasi}

\section{Tampilan Menu Login}

Pada menu login sebagai akses nama user dan password kepada untuk menuju ke menu utama.

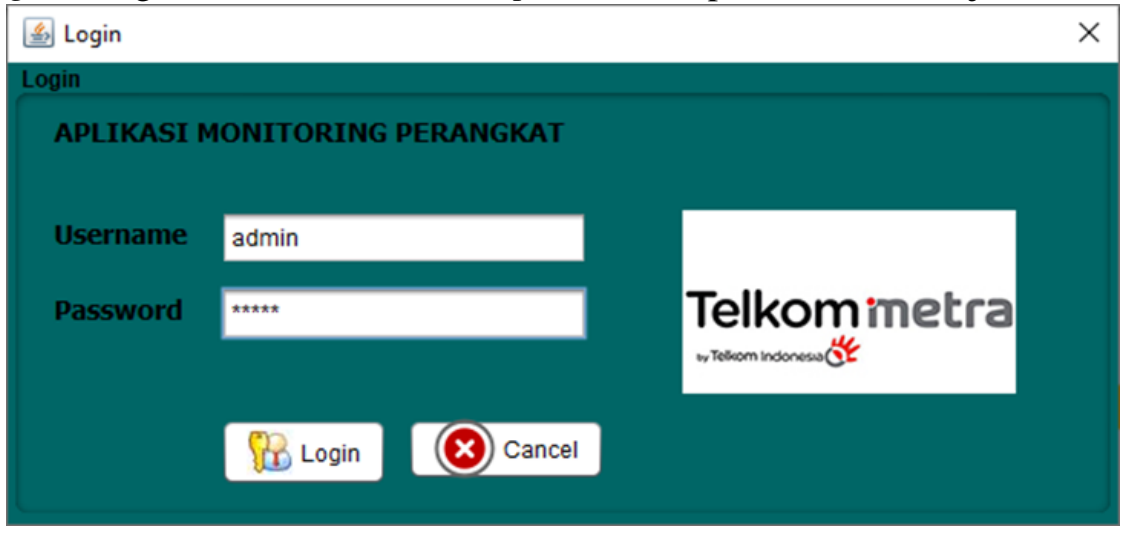

Gambar 4. Tampilan Menu Login 


\section{Tampilan Menu Utama}

Pada menu utama menyediakan berbagai menu yang dapat diakses oleh pengguna.

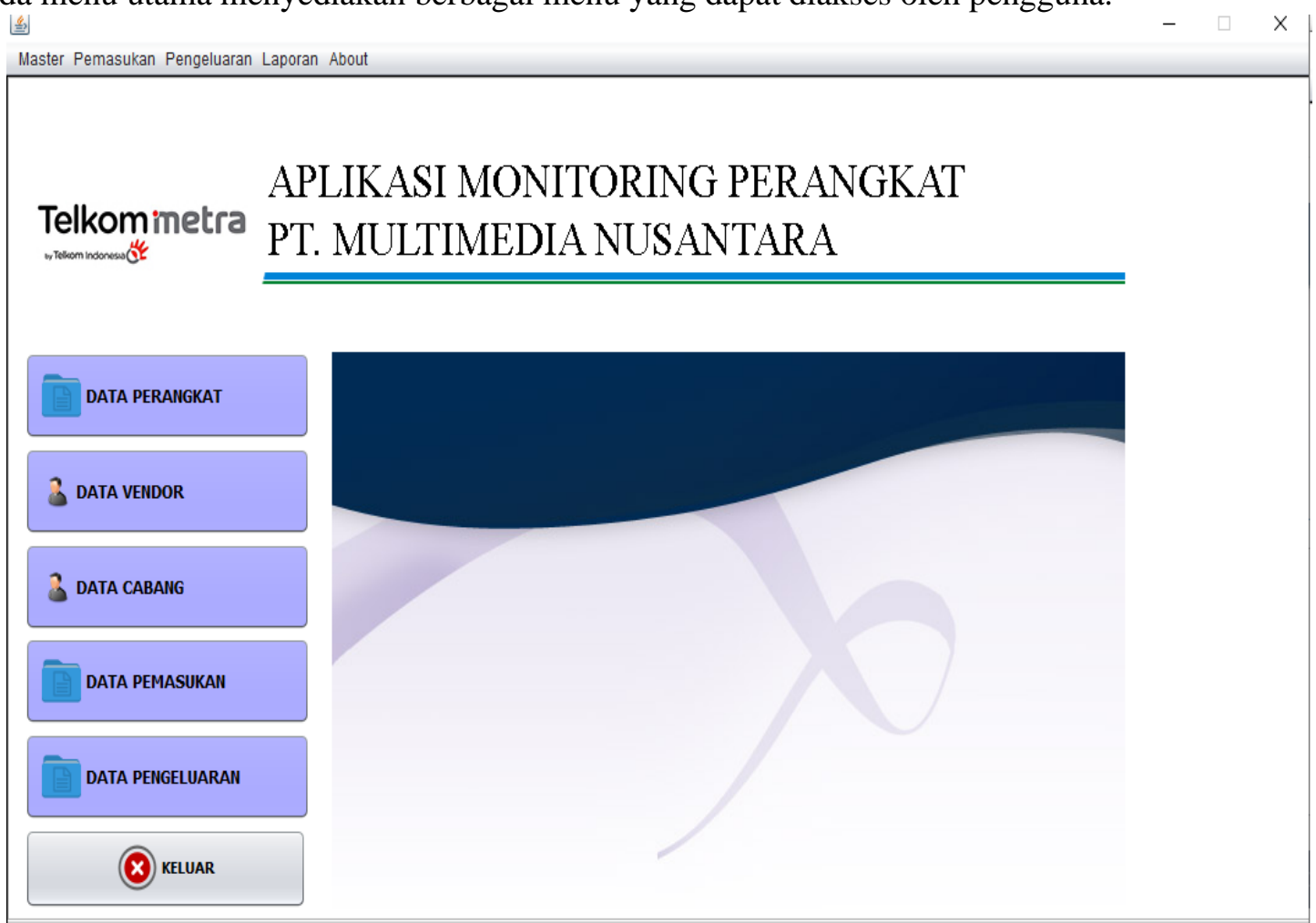

Gambar 5. Tampilan Menu Utama

\section{Tampilan Menu Data Perangkat}

Dalam menu data perangkat ini, user menginput data perangkat yang berhubungan dengan sistem informasi monitoring progres perangkat.

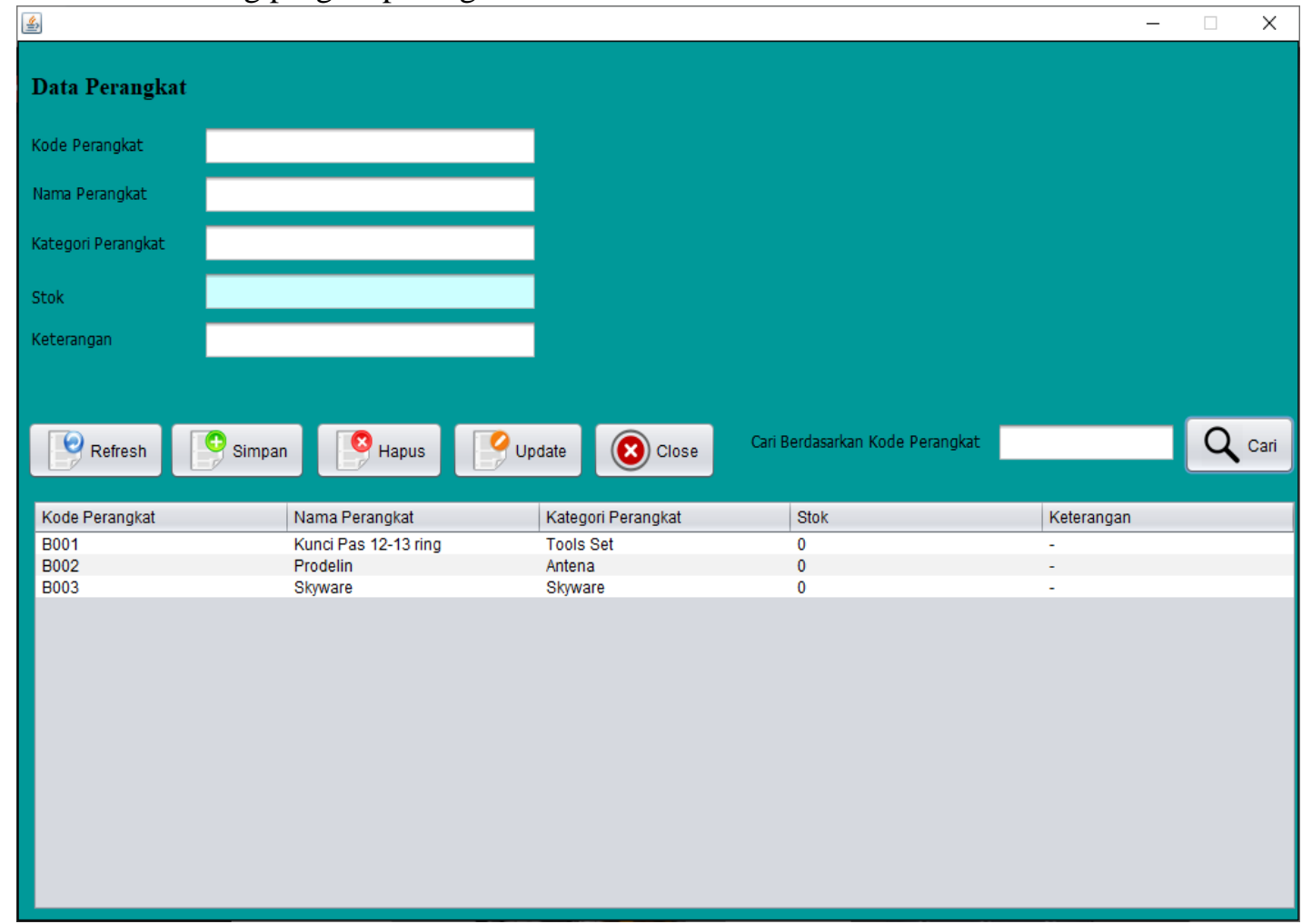

Gambar 6. Tampilan Menu Data Perangkat 


\section{Tampilan Menu Data Pemasukan Perangkat}

Dalam menu data pemasukan perangkat ini, pengguna mengisikan data-data pemasukan perangkat yang berhubungan dengan sistem informasi monitoring progres perangkat.

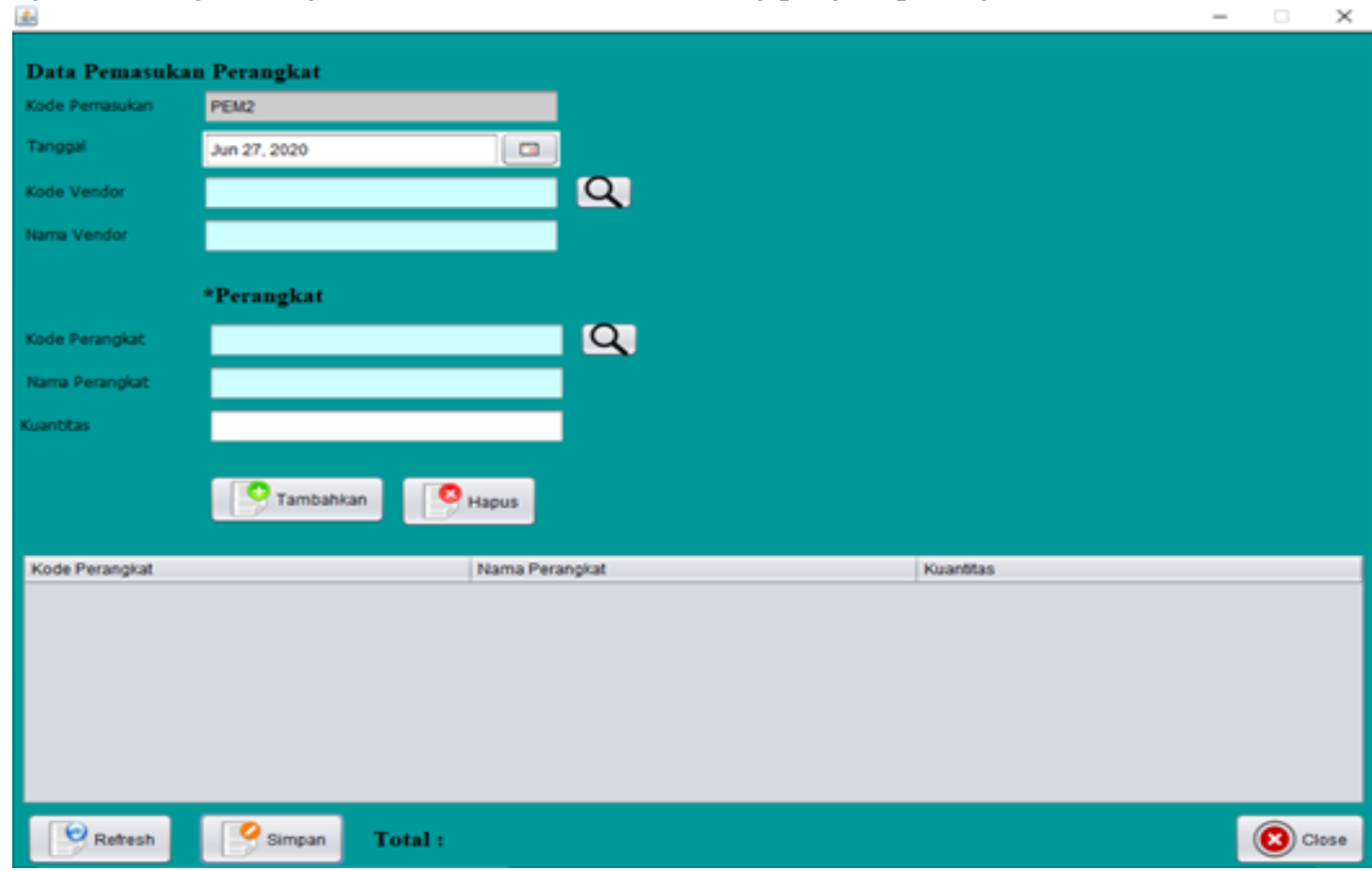

Gambar 7. Tampilan Menu Data Pemasukan Perangkat

\section{Tampilan Laporan Data Pemasukan Perangkat}

Dalam laporan data pemasukan perangkat per tanggal ini, user akan mencetak laporan data pemasukan perangkat per tanggal yang akan diserahkan kepada pimpinan.

\begin{tabular}{|c|c|c|c|c|}
\hline Kode Pemasukan & Tanggal & Kode Vendor & Nama Vendor & Total Pemasukan \\
\hline PEM & $2020-06-27$ & v001 & Aslimindo & 73 \\
\hline
\end{tabular}




\section{SIMPULAN}

Pada aplikasi pemantauan progres perangkat yang telah dikembangkan dapat menunjang pengolahan data perangkat, data vendor, data cabang, data pemasukan perangkat dan pengeluaran perangkat. Menyajikan informasi secara cepat mengenai perangkat. Aplikasi yang terstruktur dalam mengolah dan menyimpan data-data yang tersedia. Aplikasi yang dibuat memudahkan penggunaan dalam mengolah dan menyimpan data serta menjamin keamanan data tersebut.

\section{DAFTAR PUSTAKA}

Ai Rohayati. (2014). Pengaruh Kepuasan Kerja Terhadap Organizational Citizenship Behavior. In A. Rohayati, Studi Pada Yayasan Masyarakat Madani Indonesia (pp. 20-38). Jakarta: Smart- Study \& Manajement Recearch. Azhar Susanto. (2013). Sistem Informasi Akuntansi. Bandung: Lingga Jaya. Hutahaean, Jeperson. (2015). Sistem Informasi Manajemen. Yogyakarta: Graha Ilmu. Mulyani, Sri. (2016). Sistem Informasi Manajemen. Bandung: Abdi Sistematika.

Romney, paul john steninbart. (2015). Accounting information systems. England: pearson educations Limited. Sugiyono. (2011). Metode Penelitian Kuantitatif, Kualitatif dan R\&D. Bandung: Afabeta.

Sukamto, R. A. (2014). Rekayasa Perangkat Lunak Terstruktur Dan Berorientasi Objek. Bandung: Informatika Bandung. Sutabri, Tata. (2012). Analisis Sistem Informasi. Yogyakarta: Andi.

Tyoso, Jaluanto Sunu Punju. (2016). Sistem Informasi Manajemen. Jakarta: Deepublish. Yakub. (2012). Pengantar Sistem Informasi. Yogyakarta: Graha Ilmu. 